\title{
İyi tarım uygulamalarına geçen işletmelerin gelirlerindeki değişimin ve iyi tarım desteğinin yeterlilik düzeyinin belirlenmesi"
}

\section{Determination of the changes in incomes of the farms converted to good agricultural practices and the competence level of good agricultural support}

\author{
Gamze AYDIN ERYILMAZ ${ }^{1}$, Osman KILIÇ ${ }^{2}$ \\ ${ }^{1}$ Ondokuz Mayıs Üniversitesi, Samsun Meslek Yüksekokulu, Park ve Bahçe Bitkileri Bölümü, Samsun \\ ${ }^{2}$ Ondokuz Mayıs Üniversitesi, Ziraat Fakültesi, Tarım Ekonomisi Bölümü, Samsun \\ Sorumlu yazar (Corresponding author): G. A. Eryılmaz, e-posta (e-mail): gamzeaydin@omu.edu.tr \\ Yazar(lar) e-posta (Author e-mail): okilic@omu.edu.tr
}

\section{MAKALE BİLGİSI}

Alınış tarihi 27 Şubat 2018

Düzeltilme tarihi 31 Mayıs 2018

Kabul tarihi 06 Haziran 2018

\section{Anahtar Kelimeler:}

İyi tarım uygulamaları

İyi tarım desteği

Hedef programlama

\begin{abstract}
ÖZ
Araştırmanın amacı, Samsun ili Bafra ilçesinde konvansiyonel tarımdan iyi tarım uygulamalarına geçen işletmelerin gelirlerindeki değişimi ve iyi tarım desteğinin yeterlilik düzeyini ortaya koymaktır. Araştırma verileri, konvansiyonel tarım yapan 60 işletme ile iyi tarım uygulamaları yapan 17 işletmeden anket yoluyla elde edilmiștir. Veriler; 5-39 da, 40-79 da ve 79 dekardan fazla araziye sahip işletmeler ile işletmeler ortalamasına göre analiz edilmiştir. Araştırmada konvansiyonel tarım için en yüksek gelirli işletme organizasyonu doğrusal programlamayla, iyi tarım uygulamalarına yönelik işletme organizasyonu ise hedef programlamayla tespit edilmiştir. İyi tarım uygulamalarına geçen işletmelerin gelirlerindeki değişim, doğrusal programlama ile hedef programlama sonucu elde edilen brüt kâr arasındaki farka göre ortaya konulmuştur. İyi tarım uygulamalarına geçen işletmelerdeki brüt kâr, konvansiyonel tarımdaki optimum brüt kâra göre işletme büyüklük grupları itibariyle \% 8.84 $\left(99.18 \mathrm{TL} \mathrm{da}^{-1}\right), \% 8.26\left(97.61 \mathrm{TL} \mathrm{da}^{-1}\right), \% 9.09\left(88.24 \mathrm{TL} \mathrm{da}^{-1}\right)$ ve ișletmeler ortalamasına göre \% $8.60\left(92.56 \mathrm{TL} \mathrm{da}^{-1}\right)$ azalmaktadır. Brüt kârdaki bu azalmanın, işletme büyüklük gruplarında $\% 50.42, \% 51.23$ ve $\% 56.66$ 's1, ișletmeler ortalamasında ise $\% 54.02$ 'si iyi tarım desteğiyle karşılanmaktadır. Bu sonuçlara göre, iyi tarım uygulamalarına geçişin teşvik edilmesi için, verilen desteğin işletme büyüklüklerini de dikkate alacak şekilde ve en az brüt kâr kaybını karşılayacak düzeye çıkartılması gerekmektedir.
\end{abstract}

\section{ARTICLE INFO}

Received 27 February 2018

Received in revised form 31 May 2018 Accepted 06 June 2018

Keywords:

Good agricultural practices Good agricultural support

Goal programming

\begin{abstract}
The aim of this research is to reveal the changes in the incomes of farms converted from conventional agriculture to good agricultural practices, and to determine the sufficiency level of good agricultural support. The data in this research was obtained from 60 farms performing conventional agriculture and 17 farms performing good agricultural practices by questionnaires. The data was analyzed according to the three groups such as owning 5-39 decares, 40-79 decares, more than 79 decares land size, and the average of farms. In the study, the highest-income farm organization for conventional agriculture was identified by linear programming, and farm organization for good agricultural practices was identified by goal programming. The change in the revenues of farms converted to good agriculture practices was determined according to the difference between gross profits obtained by linear programming and goal programming. It was revealed that gross profit in farms converted to good agriculture practices in comparison to gross profit in enterprises adopting conventional

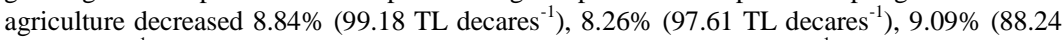
$\mathrm{TL}$ decares $\left.^{-1}\right)$ for the farm size groups, and $8.60 \%\left(92.56 \mathrm{TL}^{-1 e c a r e s}{ }^{-1}\right)$ for the average of farms. These decreases in the gross profit are compensated by good agricultural support as $50.42 \%, 51.23 \%$ and, $56.66 \%$ in farm size groups, and $57.02 \%$ in the average of farms. According to the results, the support should be increased to the level that covers the gross profit loss by considering farm sizes for encouraging the conversion to good agricultural practices.
\end{abstract}

\footnotetext{
* Doktora tezinden üretilmiștir.
} 


\section{Giriş}

Konvansiyonel tarım, geçmişte sürdürülebilir bir tarımsal uygulama şekli olarak algılanması ve yoğun girdi kullanmak suretiyle yüksek verim sağlanması nedeniyle 2000'li yılların başına kadar önceliğini korumuştur. Ancak konvansiyonel tarımda gereğinden fazla kullanılan kimyasallarla zamanla çevrenin yenilenebilir kapasitesi aşılmış, buna bağlı olarak çevresel sorunlar artarak devam etmiştir. Diğer taraftan gıda kaynaklı hastalıkların gündeme gelmesi, tarımda doğru zaman ve yeterli miktarda girdi uygulamalarına işaret eden yeni tarım sistemlerine olan arayışı hızlandırmıştır. Bu bağlamda kimyasal girdi kullanımının insan sağlığına ve çevreye zarar vermeyecek şekilde tatbik edildiği iyi tarım uygulamaları (ITTU), konvansiyonel tarıma alternatif bir üretim şekli olarak ortaya çıkmıştır (Hasdemir 2011).

Dünyada tarladan sofraya gıda güvenliği ve kalitesinin sağlanması amaciyla, ilk defa 1997'de Avrupa perakendeciler ürün çalışma grubu tarafindan iyi tarım uygulamalarının çerçevesi belirlenmiştir (Polat 2014). Türkiye'de iyi tarım uygulamalarına ilişkin ilk yönetmelik 2004'de yayınlanmış, üretime ise 2007 'de başlanmıştır (Aba ve Işın 2014). İyi tarım uygulamalarının teşvik edilmesine yönelik ilk destekleme ödemesi 2010'da yapılmıştır. Destek miktarı 2017 yılı itibariyle meyve ve sebze üretiminde dekara $50 \mathrm{TL}$, örtü altı yetiştiricilikte dekara $150 \mathrm{TL}$, süs bitkileri ve tıbbi aromatik bitkilerde dekara 100 TL olarak belirlenmiştir (Anonim 2017). Verilen desteğin iyi tarım uygulamalarının benimsenmesine ve yaygınlaşmasına katkı sağlayacağı açıktır. Ancak kimyasal girdi kullanımına getirilen kisitlamalar neticesinde, verimdeki azalmaya bağlı olarak oluşan gelir kaybını karşılamada, iyi tarım desteğinin yeterliliği konusu gündemdeki yerini korumaktadır.

Dünyada özellikle son on yılda artış gösteren sürdürülebilir tarım sistemleri konusundaki araştırmalarda gelir artışıyla birlikte işgücü, sulama suyu ve gübre (Mansoori ve ark. 2009); üretim maliyeti, sulama suyu, gübre ve ilaç (Jafari ve ark. 2008) ile işgücü, sulama suyu ve makine kullanımını (Sharma ve ark. 2007) azaltmayı hedefleyen modeller oluşturulmuştur. Türkiye'de ise iyi tarım uygulamalarıyla kimyasal girdi kullanımına getirilen kısıtlamaların, verim ve buna bağlı olarak gelir üzerindeki etkisinin ortaya konulması önemli bir sorundur. $\mathrm{Bu}$ araştırmanın amacı, Samsun ili Bafra ilçesinde konvansiyonel tarım yapan işletmelerin iyi tarım uygulamalarına geçmeleri halinde gelirlerindeki değişimin ortaya konulması ve ayrıca iyi tarım uygulamalarıyla işletme gelirindeki olası azalmanın karşılanmasında iyi tarım desteğinin yeterlilik düzeyinin belirlenmesidir. Araştırma sonuçlarının bu eksikliği gidermesi ve çözüm önerilerinin geliştirilmesine katk1 sağlaması ümit edilmektedir.

\section{Materyal ve Yöntem}

Araştırmanın ana kitlesini, Samsun ili Bafra ilçesinde 5 dekar ve daha fazla araziye sahip 4.5 bin konvansiyonel tarım yapan işletme oluşturmaktadır. Anket yapılan işletme sayısının belirlenmesinde, Neyman tabakalı tesadüfi örnekleme yöntemi kullanılmıştır (Yamane 1967). Örnekleme birimi olarak işletme arazisi büyüklüğü esas alınmıştır. Buna göre anket sayısı, işletme büyüklük gruplarına göre sırasıyla 26 (1. grup), 13 (2. grup) ve 21 (3. grup) olmak üzere 60 işletme olarak belirlenmiştir. Ayrıca bölgede iyi tarım uygulamaları yapan 286 işletmeyi girdi-çıktı katsayıları açısından temsil eden ve iyi tarım ürünlerinin tamamına yer veren 17 işletmeyle görüşülmüştür. Konvansiyonel tarım yapan işletmelere ilişkin nüfus, yaş, eğitim, işgücü varllğı, işletme arazisi büyüklüğü, arazi mülkiyet durumu, gelirler ve masraflar elde edilmiştir. Arazi büyüklük gruplarına göre işletmelere ait sosyo-ekonomik özellikler arasındaki farklılık, tek yönlü varyans analiziyle test edilmiştir.

Araştırmada üç aşamalı yapılan analizlerin birincisinde, konvansiyonel tarım yapan işletmelerde en yüksek gelirli işletme organizasyonu doğrusal programlamayla belirlenmiştir. Modelin amaç fonksiyonu, her bir üretim faaliyetine ait gayri safi üretim değerinden, değişken masrafların çıkarılmasıyla elde edilen brüt kârları kapsamaktadır. Modeldeki sınırlayıcı faktörler ise arazi, ahır kapasitesi, işgücü, münavebe ve pazarlamadır. Araştırmada konvansiyonel tarım yapan işletmelerin, mevcut işgücü ve sermaye varlıklarıyla iyi tarım uygulamalarına geçtikleri kabul edilerek diğer aşamalara geçilmiştir. Analizin ikinci aşamasında, brüt kâr hedefiyle birlikte kimyasal girdi kullanımını sınırlandıran iyi tarım uygulamalarına ilişkin işletme organizasyonuna hedef programlamayla (HP I) ulaşılması amaçlanmıştır. Ancak HP I sonucundaki işletme organizasyonunda hedeflenen brüt kâra ulaşılamadığ 1 gibi azot, fosfor, potasyum, herbisit, fungusit ve insektisit hedeflerinden bazıları sınırlandırılan miktarları aşmıştır. Bunun için yapılan üçüncü aşamada, HP I'deki brüt kâr kademeli olarak azaltılarak sınırlandırılan miktarlarda kimyasal girdi kullanıldığında elde edilecek brüt kâr, ikinci defa yapılan hedef programlamayla (HP II) tespit edilmiştir (Çizelge 1). Araştırmada iyi tarım uygulamalarına geçen işletmelerin ekonomik kaybı, doğrusal programlamayla elde edilen brüt kâr ile HP II sonucu elde edilen brüt kâr arasındaki fark kadardır. İyi tarım desteğinin, işletmelerin ekonomik kaybını tamamen karşılaması halinde $\% 100$ yeterli olacağı kabul edilmiştir.

Çizelge 1. Araştırmanın metodolojisi.

Table 1. Research methodology.

\begin{tabular}{lcl}
\hline $\begin{array}{l}\text { Konvansiyonel tarım } \\
\text { yapan işletmeler }\end{array}$ & 1. Aşama & $\begin{array}{l}\text { Doğrusal programlama } \\
\text { (Amaç: Optimum brüt kâr) }\end{array}$ \\
\hline İTU yapan işletmeler & 2. Aşama & $\begin{array}{l}\text { Hedef programlama (HP I) } \\
\text { (Hedef: Ekonomik + Çevresel) } \\
\text { Hedef programlama (HP II) } \\
\text { (Hedef: Çevresel) }\end{array}$ \\
\hline
\end{tabular}

Hedef programlamada amaç fonksiyonu,

$$
\min z=\sum_{j=1}^{m}\left(d_{j}^{-}, d_{j}^{+}\right)
$$

hedef kısıtlarına ilişkin fonksiyon ise

$$
\left(\sum_{i=1}^{n} a_{i j} x_{i}\right)+d_{j}^{-}-d_{j}^{+}=b_{j} ; j=1,2,3 \ldots m
$$

şeklinde gösterilmektedir. Formüllerde yer alan $x_{i}$ karar değişkenini, $a_{i j}$ hedeflere ilişkin karar değişkeninin katsayılarını, $b_{j}$ hedeflenen değeri, $d_{j}^{+}$hedefin üzerindeki sapma değişkenini, $d_{j}^{-}$ise hedefin altındaki sapma değişkenini ifade etmektedir. Buna göre modelin amaç fonksiyonu, brüt kâr hedefinin altında kalan sapma ile azot, fosfor, potasyum, herbisit, fungusit ve insektisit hedeflerinin üzerine çıan sapmaların minimize edilmesi şeklinde belirlenmiştir (Çizelge 2). 
Çizelge 2. İyi tarım uygulamalarında ekonomik ve çevresel hedefler.

Table 2. Economic and environmental goals in good agricultural practices.

\begin{tabular}{|c|c|c|c|}
\hline \multicolumn{2}{|c|}{ Hedefler } & Açıklama & Hedeflerin belirlenmesi \\
\hline 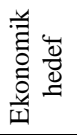 & Brüt kâr & $\begin{array}{l}\text { İyi tarım uygulamalarıyla meydana gelen brüt kâr kaybının, iyi } \\
\text { tarım desteğiyle karşılanması }\end{array}$ & $\begin{array}{l}\text { Konvansiyonel tarım yapan işletmelerdeki optimum brüt } \\
\text { kârdan, } 2014 \text { yılı itibariyle verilen iyi tarım desteği ( } 50 \\
\text { TL da }^{-1} \text { ) çıkarılmıştır. }\end{array}$ \\
\hline 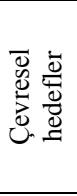 & $\begin{array}{l}\text { Azot } \\
\text { Fosfor } \\
\text { Potasyum } \\
\text { Herbisit } \\
\text { Fungusit } \\
\text { İnsektisit }\end{array}$ & $\begin{array}{l}\text { Bitkilerde yaprak ve gövde oluşumu } \\
\text { Bitkilerde çiçeklenme, kök gelişimi, tohum ve meyve oluşumu } \\
\text { Bitkinin su dengesinin düzenlenmesi } \\
\text { Yabancı ot gelişimininin engellenmesi } \\
\text { Mantar gelişiminin engellenmesi } \\
\text { Böcek gelişiminin engellenmesi }\end{array}$ & $\begin{array}{l}\text { İyi tarım uygulamalarının izin verdiği etkili madde } \\
\text { miktarları esas alınmıştır. }\end{array}$ \\
\hline
\end{tabular}

\section{Bulgular ve Tartış̧ma}

Konvansiyonel tarım yapan işletme yöneticilerinin ortalama yaşı 57.67, eğitim gördükleri yıl sayısı 5.40, tarımsal deneyimleri ise 33.63 yıldır. Yöneticilerin eğitim süreleri ve tarımsal deneyimleri açısından, işletme büyüklük grupları arasındaki farklılık istatistiksel olarak önemlidir $(\mathrm{p}<0.01)$. En yüksek işletme dışı tarımsal gelire sahip olan yönetici, 13.24 bin TL ile birinci grupta yer almaktadır. İşletme dışı tarımsal gelir açısından, işletme büyüklük grupları arasındaki farklılık istatistiksel olarak önemli değildir $(\mathrm{p}>0.01)$. İşletmelerde aile nüfusu 5.13 kişi, aile işgücü ise erkek işgücü birimi (EİB) cinsinden 3.13 'tür. İşletme arazisi miktarı, işletme büyüklük gruplarına göre sırasıyla 46.08, 59.73, 146.42 ve işletmeler ortalamasında 84.16 dekardır (Çizelge 3).

İşletme arazisinin \% 93.50'si tarla arazisine ait olup, geriye kalanı sebze ve meyve bahçesi ile boş bırakılan araziden oluşmaktadır. İşletme arazisinin \% 30.38 ile en büyük kısmında çeltik ekilidir. Bunu \% 13.08 ile buğday+kışlık sebze, \% 11.81 ile buğday üretim faaliyeti takip etmektedir. İşletmeler ortalamasına göre hayvan varlığı, büyükbaş hayvan birimi (BBHB) cinsinden $7.88^{\prime}$ 'dir. İşletmelerde büyükbaş, küçükbaş ve kanatlı hayvan olarak yapılan hayvan yetiştiriciliği, büyük ölçüde aile tüketimini karşılamaya yöneliktir.

İşletmelerde gayri safi üretim değeri, işletmeler ortalamasında 112.78 bin TL olup, bunun \% 86.76's1 bitkisel üretim faaliyetlerinden elde edilmektedir (Çizelge 4). Bölgede daha önce yapılan bir araştırmada, bitkisel üretim değerinin payı
\% 81.50 olarak bulunmuştur (Şili ve Gündüz 2014). İşletmelerde mevcut durumda işletme başına 67.36 bin TL olan brüt kâr, planlama sonucunda \% 34.41 oranında artarak 90.54 bin TL olmuştur (Çizelge 4).

Konvansiyonel tarım yapan işletmelerde girdi kullanımı, büyük ölçüde işletme yöneticisinin geçmişteki tecrübelerine göre yapılmaktadır. İşletmelerde genellikle aynı çeşit kimyasal gübre tercih edilmekte, ürünlerde oluşan hastalık, zararlı ve yabancı otlarla mücadele konusunda çoğunlukla zirai ilaç bayilerinden bilgi alınmaktadır. İyi tarım uygulamaları yapan işletmelerde ise konvansiyonel tarımdan farklı olarak üretimin her aşaması kayıt altına alınmakta, tarımsal uygulamaların tamamı Gıda, Tarım ve Hayvancılık Bakanlığı İl ve İlçe Müdürlükleri tarafindan kontrol edilmektedir. Gübreleme ve ilaçlama faaliyetleri, çiftçilere verilen eğitimler doğrultusunda uygun zaman ve doğru üretim teknikleriyle yapılmaktadır. İyi tarım uygulamalarında toprak analizi zorunlu olup, analiz sonuçlarına göre gübre kullanılmaktadır. Konvansiyonel tarım yapan işletmelerde azot, fosfor ve potasyum kullanımları, işletmeler ortalamasına göre sirasıyla dekara 44.08, 21.28 ve $1.67 \mathrm{~kg}$ 'dır. İşletmelerin iyi tarım uygulamalarına geçmeleri halinde kullanilan azot $\% 28.25$, fosfor $\% 42.02$ ve potasyum $\% 49.20$ oranında azalmaktadır. Ayrıca konvansiyonel tarımda, işletmeler ortalamasına göre dekara $0.14,0.12$ ve $0.05 \mathrm{~kg}$ olarak uygulanan herbisit, insektisit ve fungusit, iyi tarım uygulamalarına geçtikten sonra sırasıyla \% 48.97, \% 24.14 ve \% 34.45 daha az kullanılmaktadır.

Çizelge 3. İşletme yöneticisi ve işletmeye ait özellikler.

Table 3. Characteristics of farmer and farm.

\begin{tabular}{|c|c|c|c|c|}
\hline İşletme yöneticilerine ait özellikler & 1. grup & 2. grup & 3. grup & İşletmeler ortalaması \\
\hline Yaş (y1l) & 55.88 & 60.69 & 58.00 & 57.67 \\
\hline Eğitim süresi (y1l)* & $4.84^{\mathrm{b}}$ & $5.62^{\mathrm{b}}$ & $5.95^{\mathrm{a}}$ & 5.40 \\
\hline Tarımsal deneyim (y1l)* & $33.76^{\mathrm{a}}$ & $34.85^{\mathrm{a}}$ & $32.71^{\mathrm{b}}$ & 33.63 \\
\hline İşletmede çalışılan süre (ay y1l ${ }^{-1}$ ) & 11.73 & 11.69 & 12.00 & 11.88 \\
\hline İşletme dişı tarımsal gelir (bin TL y1l ${ }^{-1}$ ) & 13.24 & 10.49 & 10.60 & 11.72 \\
\hline Tarım dışı gelir (bin TL yı1 ${ }^{-1}$ ) & 6.15 & 7.47 & 7.15 & 6.79 \\
\hline \multicolumn{5}{|l|}{ İşletmelere ait özellikler } \\
\hline Aile nüfusu (kişi) & 4.58 & 5.52 & 5.62 & 5.13 \\
\hline Aile işgücü (EİB) & 2.61 & 3.31 & 3.67 & 3.13 \\
\hline Hayvan varlığg (BBHB) & 7.27 & 5.29 & 10.25 & 7.88 \\
\hline Mülk arazisi (da) * & $23.56^{\mathrm{c}}$ & $51.85^{\mathrm{b}}$ & $120.52^{\mathrm{a}}$ & 63.63 \\
\hline Kiralanan arazi (da) & 20.33 & 12.73 & 24.76 & 20.23 \\
\hline Ortağa tutulan arazi (da) & 2.19 & - & 4.76 & 2.62 \\
\hline Kiraya/ortağa verilen arazi (da) & - & 4.85 & 3.62 & 2.32 \\
\hline İşletme arazi $(\mathrm{da}) *$ & $46.08^{\mathrm{c}}$ & $59.73^{\mathrm{b}}$ & $146.42^{\mathrm{a}}$ & 84.16 \\
\hline
\end{tabular}

*İşletme büyüklük grupları arasındaki fark \% 1 önem düzeyinde istatistiksel olarak önemlidir. 
Çizelge 4. Konvansiyonel tarım yapan işletmelerde brüt kâr.

Table 4. Gross profit in conventional agricultural farms.

\begin{tabular}{|c|c|c|c|c|c|c|c|c|}
\hline & \multicolumn{4}{|c|}{ Mevcut durum } & \multicolumn{4}{|c|}{ Planlama sonucu } \\
\hline & 1. grup & 2. grup & 3. grup & $\begin{array}{l}\text { İşletmeler } \\
\text { ortalaması }\end{array}$ & 1. grup & 2. grup & 3. grup & $\begin{array}{l}\text { İşletmeler } \\
\text { ortalamas } 1\end{array}$ \\
\hline$\overline{\text { Bitkisel üretim değeri (+) }}$ & 47.13 & 74.88 & 174.86 & 97.85 & 73.28 & 98.15 & 253.12 & 126.15 \\
\hline Hayvansal üretim değeri & 13.63 & 11.94 & 18.40 & 14.93 & 18.99 & 20.46 & 21.69 & 20.21 \\
\hline Gayri safi üretim değeri & 60.76 & 86.82 & 193.26 & 112.78 & 92.27 & 118.60 & 274.81 & 146.36 \\
\hline Değişken masraflar (-) & 27.53 & 34.50 & 74.53 & 45.42 & 40.85 & 48.02 & 132.74 & 55.82 \\
\hline Brüt kâr (bin TL işletme ${ }^{-1}$ ) & 33.23 & 52.32 & 118.73 & 67.36 & 51.72 & 70.58 & 142.07 & 90.54 \\
\hline
\end{tabular}

Birinci gruptaki işletmelerin iyi tarım uygulamalarına geçmeleri halinde HP I sonucuna göre, hedeflenen brüt kârdan işletme başına $0.71 \mathrm{TL}$ daha düşük brüt kâr elde edilmekte, fosfor, herbisit ve fungusit hedeflenen miktarlardan 16.42, 0.04 ve $0.35 \mathrm{~kg}$ daha fazla kullanılmaktadır. İkinci gruptaki işletmelerde brüt kâr hedefi, HP I sonucuna göre büyük oranda gerçekleşmektedir. Ancak azot, fosfor, herbisit, fungusit ve insektisit kullanımı hedeflenen miktarlardan sirasıyla 65.52, $42.32,0.07,0.19$ ve $0.09 \mathrm{~kg}$ daha fazladır. Üçüncü gruptaki işletmelerin iyi tarım uygulamalarına geçtiklerinde elde ettikleri brüt kâr, işletme başına hedeflenenden 1.94 bin TL daha azdır. Diğer taraftan fosfor, herbisit ve fungusit hedeflenen miktarlardan sirasiyla $14.20,0.79$ ve $0.37 \mathrm{~kg}$ daha fazla kullanılmaktadır. İşletmeler ortalamasında HP I sonucuna göre hedefin 0.81 bin TL altında brüt kâr elde edilirken, fosfor, herbisit ve fungusit miktarları ise kullanılması gereken azami miktarların üzerinde uygulanmaktadır (Çizelge 5). Irak'ta yapılan bir araştırmaya göre gübre ve sulama suyu kullanımı fazla olduğunda, işletmenin brüt kâr marjı da daha yüksektir (Mansoori ve ark. 2009). Yunanistan'da yapılan bir araştırmaya göre, ekonomik hedefe öncelik verildiği durumda, hedeflenen miktardan daha fazla gübre kullanılmaktır (Latinapolous ve Mylopoulos 2005).
Hedef programlama II sonucuna göre, konvansiyonel tarım yapan işletmelerdeki optimum brüt kâr, iyi tarım uygulamalarına geçildikten sonra işletme büyüklük gruplarında \% $8.84\left(99.18 \mathrm{TL} \mathrm{da}^{-1}\right), \% 8.26$ (97.61 $\left.\mathrm{TL} \mathrm{da}^{-1}\right), \% 9.09$ (88.24 $\left.\mathrm{TL} \mathrm{da}^{-1}\right)$ ve işletmeler ortalamasında \% $8.60\left(92.56 \mathrm{TL} \mathrm{da}{ }^{-1}\right)$ azalmaktadır (Çizelge 6). İyi tarım uygulamalarıyla oluşan bu ekonomik kaybın verilen destekle karşılanma oranı, işletme büyüklük grupları ve işletmeler ortalamasında sırasıyla $\% 50.42, \% 51.23, \% 56.66$ ve \% 54.02 olmaktadır.

\section{Sonuç ve Öneriler}

Araştırma alanında iyi tarım uygulamalarına geçen işletmelerin brüt kârlarında meydana gelen azalma, iyi tarım desteğiyle tamamen karşılanamadığı gibi desteğin yeterlilik oranı işletme büyük gruplarına göre farklılık göstermektedir. Tarımsal faaliyetlerden kaynaklanan çevresel sorunların azaltılması ve doğal kaynakların tahrip edilmeden gelecek nesillere aktarılmasında, ekonomik kaybın işletme büyüklüklerini de dikkate alınacak şekilde iyi tarım desteğiyle karşılanması gerekmektedir. Ayrıca iyi tarım uygulamaları desteği, bütün bitkisel ürünleri kapsayacak şekilde genişletilmelidir.

Çizelge 5. İTU hedefleri, ulaşıllan değerler ve sapma değişkenler (d// $\left.\mathrm{d}^{+}\right)$(HP I).

Table 5. Goals in good agricultural practices, values reached and deviation variables ( $\left.\mathrm{d}^{-} / \mathrm{d}^{+}\right)$(Goal Programming I).

\begin{tabular}{|c|c|c|c|c|c|c|c|c|}
\hline & \multicolumn{2}{|c|}{ 1. grup } & \multicolumn{2}{|c|}{ 2. grup } & \multicolumn{2}{|c|}{ 3. grup } & \multicolumn{2}{|c|}{ İşletmeler ortalaması } \\
\hline & Hedef & $\begin{array}{c}\text { Ulaşılan } \\
\text { değer }\end{array}$ & Hedef & $\begin{array}{c}\text { Ulaşılan } \\
\text { değer }\end{array}$ & Hedef & $\begin{array}{c}\text { Ulaşılan } \\
\text { değer }\end{array}$ & Hedef & $\begin{array}{c}\text { Ulaşılan } \\
\text { değer }\end{array}$ \\
\hline Brüt kâr (bin TL işletme ${ }^{-1}$ ) & 49.42 & $\begin{array}{c}48.71 \\
\left(d^{-}=0.71\right)\end{array}$ & 67.59 & $\begin{array}{c}67.57 \\
\left(d^{-}=0.02\right)\end{array}$ & 134.75 & $\begin{array}{c}132.81 \\
\left(\mathrm{~d}^{-}=1.94\right)\end{array}$ & 86.33 & $\begin{array}{c}85.52 \\
\left(d^{-}=0.81\right)\end{array}$ \\
\hline Azot $\left(\mathrm{kg}\right.$ işletme $\left.{ }^{-1}\right)$ & 629.30 & 629.30 & 779.76 & $\begin{array}{c}845.28 \\
\left(\mathrm{~d}^{+}=65.52\right)\end{array}$ & 2206.79 & 2206.79 & 1238.63 & 1238.63 \\
\hline Fosfor ( $\mathrm{kg}$ işletme $\left.{ }^{-1}\right)$ & 245.16 & $\begin{array}{c}261.58 \\
\left(\mathrm{~d}^{+}=16.42\right)\end{array}$ & 300.52 & $\begin{array}{c}342.84 \\
\left(\mathrm{~d}^{+}=42.32\right)\end{array}$ & 847.36 & $\begin{array}{c}861.56 \\
\left(\mathrm{~d}^{+}=14.20\right)\end{array}$ & 482.73 & $\begin{array}{c}513.37 \\
\left(\mathrm{~d}^{+}=30.64\right)\end{array}$ \\
\hline Potasyum ( $\mathrm{kg}$ işletme ${ }^{-1}$ ) & 4.97 & 4.97 & 7.06 & 7.06 & 17.89 & 17.89 & 10.99 & 10.99 \\
\hline Herbisit ( $\mathrm{kg}$ işletme ${ }^{-1}$ ) & 0.55 & $\begin{array}{c}0.59 \\
\left(\mathrm{~d}^{+}=0.04\right)\end{array}$ & 0.61 & $\begin{array}{c}0.68 \\
\left(\mathrm{~d}^{+}=0.07\right)\end{array}$ & 1.66 & $\begin{array}{c}2.45 \\
\left(\mathrm{~d}^{+}=0.79\right)\end{array}$ & 0.97 & $\begin{array}{c}1.21 \\
\left(\mathrm{~d}^{+}=0.24\right)\end{array}$ \\
\hline Fungusit ( $\mathrm{kg}$ işletme ${ }^{-1}$ ) & 1.03 & $\begin{array}{c}1.38 \\
\left(\mathrm{~d}^{+}=0.35\right)\end{array}$ & 1.29 & $\begin{array}{c}1.48 \\
\left(\mathrm{~d}^{+}=0.19\right)\end{array}$ & 3.94 & $\begin{array}{c}4.31 \\
\left(\mathrm{~d}^{+}=0.37\right)\end{array}$ & 2.13 & $\begin{array}{c}2.38 \\
\left(\mathrm{~d}^{+}=0.25\right)\end{array}$ \\
\hline İnsektisit $\left(\mathrm{kg}\right.$ işletme $\left.{ }^{-1}\right)$ & 1.57 & 1.57 & 2.31 & $\begin{array}{c}2.40 \\
\left(\mathrm{~d}^{+}=0.09\right)\end{array}$ & 6.65 & 6.65 & 3.63 & 3.63 \\
\hline
\end{tabular}

Çizelge 6. Çevresel hedefleri sağlayan brüt kâr ve sapma değişkeni (d) (HP II).

Table 6. Gross profit providing environmental goals and deviation variable (d)) (Goal Programming II).

\begin{tabular}{|c|c|c|c|c|}
\hline & 1. grup & 2. grup & 3. grup & İşletmeler ortalaması \\
\hline Brüt kâr (bin TL işletme ${ }^{-1}$ ) & 47.15 & 64.75 & 129.15 & 82.75 \\
\hline Sapma değişkeni (TL da $\left.{ }^{-1}\right)$ & 99.18 & 97.61 & 88.24 & 92.56 \\
\hline Azot $\left(\mathrm{kg}\right.$ işletme $\left.{ }^{-1}\right)$ & 629.30 & 779.76 & 2206.79 & 1238.63 \\
\hline Fosfor $\left(\mathrm{kg}\right.$ işletme $\left.{ }^{-1}\right)$ & 245.16 & 300.52 & 847.36 & 482.73 \\
\hline Potasyum (kg ișletme $\left.\mathrm{e}^{-1}\right)$ & 4.97 & 7.06 & 17.89 & 10.99 \\
\hline Herbisit (kg işletme $\left.{ }^{-1}\right)$ & 0.55 & 0.61 & 1.66 & 0.97 \\
\hline Fungusit (kg işletme $\left.{ }^{-1}\right)$ & 1.03 & 1.29 & 3.94 & 2.13 \\
\hline İnsektisit $\left(\mathrm{kg}\right.$ işletme $\left.{ }^{-1}\right)$ & 1.57 & 2.31 & 6.65 & 3.63 \\
\hline
\end{tabular}


Çiftçilerin iyi tarım uygulamalarını devam ettirmelerinde, Gıda, Tarım ve Hayvancılık Bakanlığı İl ve İlçe Müdürlükleri bünyesinde yürütülecek bilinçlendirme çalışmaları kapsamında, bölgedeki tarımsal faaliyetlere hâkim olan ve güncel bilgilerle sürekli eğitimlere tabi tutulan uzman bir ekibin görev alması etkili olacaktır. Ekipteki personelin teknik bilgi yönünden yeterli olmasının yanı sıra, iletişim konusundaki becerilerinin de geliştirilmesiyle çiftçilere daha kolay ve etkin bilgi transferi yapılabilecektir. Çiftçi eğitimi çalışmalarında, iyi tarım uygulamalarının insan sağlığ ve çevreye olumlu etkileri konusunda bilgiler verilmeli ve eğitimlere bölgedeki önder çiftçiler ile köy muhtarları başta olmak üzere çok sayıda çiftçinin katılımı sağlanmalıdır. Ayrıca iyi tarım ürünlerinin doğrudan tüketiciye ulaştırılması amacıyla, geniş bir tüketici kitlesine hizmet verecek şekilde üretici pazarlarının organize edilmesi gerekir.

İyi tarım uygulamaları, kısa vadeli önlemlerden ziyade sağlıklı bir toplumsal yaşamı esas alan bir felsefe olarak kabul edilmeli ve bu bilinç tarladan sofraya kadarki süreçte devam ettirilmelidir. Bunun için Gıda, Tarım ve Hayvancılık Bakanlığı başta olmak üzere, üniversiteler, tüketici organizasyonları, tarım ürünleri işleme firmaları ve medya kuruluşları gibi iyi tarım uygulamalarıyla ilgili bütün paydaşların birlikte hareket etmeleri gerekir. Böylece iyi tarım uygulamaları çevresel, ekonomik ve sosyal olmak üzere tüm yönleriyle ele alınmış ve bütün paydaşların beklentileri ortak bir noktada buluşmuş olacaktır.

\section{Kaynaklar}

Aba GÖ, Işın Ş (2014) Dünyada ve Türkiye'de iyi tarım uygulamalarının gelişimi. XI Ulusal Tarım Ekonomisi Kongresi Cilt 1, Samsun, s. 19-25.

Anonim (2017) T.C. İçişleri Bakanlığı Bafra Kaymakamlığı. http://www.bafra.gov.tr/cografi-yapi. Erişim 15 Mayıs 2017.

Hasdemir M. (2011) Kiraz yetiştiriciliğinde iyi tarım uygulamalarının benimsenmesini etkileyen faktörlerin analizi. Doktora tezi, Ankara Üniversitesi, Fen Bilimleri Enstitüsü, Ankara.

Jafari H, Koshteli OR, Khabiri B (2008) An optimal model using goal programming for rice farm. Applied Mathematical Sciences 23: $1131-1136$.

Latinapolous D, Mylopoulos Y (2005) Optimal allocation of land and water resources in irrigated agriculture by means of goal programming: Application in Loudias River Basin. Global NEST Journal 7: 264-273.

Mansoori H, Kohansal MR, Ghousi MFK (2009) Introducing a lexicographic goal programming for environmental conservation program in farm activities: A case study in Iran. China Agricultural Economic Review 4: 478-484.

Polat F (2014) Azerbaycan'da global G.A.P tarım uygulamalarının gida güvenliği Bakımından Değerlendirilmesi, Azersun Örneği. XI. Ulusal Tarım Ekonomisi Kongresi Cilt 1, Samsun, s. 128-131.

Sharma DK, Jana RK, Gaur A (2007) Fuzzy goal programming for agricultural land allocation problems. Yugoslav Journal of Operations Research, 17: 31-42.

Şili Ş, Gündüz O (2014) Samsun İli Bafra İlçesinde domates yetiştiren işletmelerin Ekonomik Analizi. XI. Ulusal Tarım Ekonomisi Kongresi Cilt 2, Samsun, s. 714-719.

Yamane T (1967) Elemantary Sampling Theory. Prentice Hall, Englewood Cliffs, Nt. 